\title{
Is Abnormally Large Volume a Clue?
}

\author{
Tsung-Hsun $\mathrm{Lu}^{1} \&$ Jun-De Lee ${ }^{2}$ \\ ${ }^{1}$ Department of Business Administration, CTBC Financial Management College, Tainan, Taiwan \\ ${ }^{2}$ Department of Marketing and Logistics Management, Ming Hsin University of Science and Technology, \\ Shin-Chu, Taiwan \\ Correspondence: Tsung-Hsun Lu, Department of Business Administration, CTBC Financial Management \\ College, No.600, Sec. 3, Taijiang Blvd., Annan District, Tainan 709, Taiwan R.O.C. Tel: 886-6-287-3335. E-mail: \\ r4895107@gmail.com
}

Received: June 21, 2016

Accepted: August 15, 2016

Online Published: August 25, 2016

doi:10.5539/ijef.v8n9p226

URL: http://dx.doi.org/10.5539/ijef.v8n9p226

\begin{abstract}
This paper investigates whether abnormal trading volume provides information about future movements in stock prices. Utilizing data from the Taiwan 50 Index from October 29, 2002 to December 31, 2013, the researchers employ trading volume rather than stock price to test the principles of resistance and support level employed by technical analysis. The empirical results suggest that abnormal trading volume provides profitable information for investors in the Taiwan stock market. An out-of-sample test and a sensitive analysis are conducted for the robustness of the results.
\end{abstract}

Keywords: trading volume, technical analysis, out-of-sample, Taiwan stock market

\section{Introduction}

Forecasting stock returns remains one of the most promising areas in financial market research. Although technical analysis (TA), together with fundamental analysis, is one of the two main forecasting approaches, few studies of TA appeared in academic literature until one of the cornerstones of academic finance, the efficient market hypothesis, encountered serious challenges by the publication of several seminal papers (Sweeney, 1986; Brock, Lakonishok, \& LeBaron, 1992). However, TA is ubiquitous in real world financial markets, where its practitioners study a stock's past prices and related summary trading statistics to predict future price trends (Brock, Lakonishok, \& LeBaron, 1992).

Whereas price and quantity are foundations of any theory of market economics, the importance of trading volume in financial markets is less studied. In this paper, we do not attempt to ascertain causality between stock price and trading volume. As to the proposition of TA, volume precedes price (Murphy, 1986). The purpose of this study is to determine whether trading volume could replace price in the technical rules of "trading range break-out" as established by Brock, Lakonishok, and LeBaron (1992) in one of the most influential papers on TA.

As Murphy (1986) notes, "technical analysis concentrates on the study of market action" and "market action discounts everything." Thus, trading volume is the footprint of ex post market action, which reveals shifts in supply and demand. Accordingly, price and volume are equilibriums generated by markets. Therefore, large trading volume most likely implies that some meaningful and noteworthy occurrence has taken place in financial markets.

Over the past decades, considerable research has investigated the price effects on profit, but trading volume has received little scholarly attention. This paper considers the profitability of short-term TA by focusing on trading volume strategies. Gervais, Kaniel, and Mingelgrin (2001) employ extreme trading volume to predict subsequent price changes, and find that extremely high volume tends to yield positive excess returns. Furthermore, Huang, Heian, and Zhang (2011) argue that the existence of a high volume premium results from two factors, differences of opinion and overconfidence.

As Nison (1997) notes, large volume initiates a counterforce that creates a reversal in stock price. However, large volume presents a dilemma for amateurs and specialists in financial markets. If it suggests "distribution," the future price is portended to fall, whereas if it reveals "accumulation," the future price is expected to advance. 
Blume, Easley, and O'Hara (1994) conclude that volume provides information about the quality of market participants' information that is never conveyed in prices. Henry and McKenzie (2006) investigate the relationship between trading volume and price volatility and find that short-selling is the source of large volume. Arguing that price and volume statistics together are more informative than price statistics alone, they suggest that TA has value because current prices do not reveal all available information.

This paper makes three main contributions. First, a support and resistance trading rule-i.e., a trading range break-out — based on volume has never been studied. Second, we reinforce our results by employing validation procedures used in standard practice, including a suitable identification of trends and the definitions of anchoring and spike effects. Third, we incorporate behavioral finance into our results for insight into large volume.

Alexander (1964) and Fama and Blume (1966) find that the profitability produced by TA is eroded by transaction costs. Park and Irwin (2007) also stress the importance of considering transactions costs, data snooping, and out-of-sample problems when testing TA's performance. Thus, without considering transaction costs, all such tests are subject to dispute. In this paper, however, we take a $1 \%$ round-trip trading cost into consideration for the trading strategies that we test. Furthermore, we also conduct out-of-sample tests by selecting 43 other stocks from the Taiwan Mid-Cap 100 index. Day and Wang (2002) speculate that using index data to test the performance of TA may be biased due to nonsynchronous trading. We therefore utilize data on the Taiwan 50 Index (TW50) component stocks rather than on the index itself.

This paper provides convincing evidence that stock price will reverse when certain trading volume patterns are present. Furthermore, we find that extremely large volume information has value for investors when they trade. The remainder of this paper is structured as follows. Section 2 reviews the literature. Section 3 describes the data and hypotheses. The research methodologies are presented in Section 4. We discuss empirical results in Section 5. Section 6 offers our conclusions.

\section{Literature Review}

Academicians have taken another look at TA following growing evidence that investors do not always make decisions rationally (Marshall, Young, \& Rose, 2006). Proponents of TA believe that shifts in supply and demand are revealed by charts and technical indicators. Practitioners divide TA into two types: visual patterns in charts and mathematical indicators by calculating (Fock, Klein, \& Zwergel, 2005). Most empirical research related to TA concerns visual patterns. Empirical evidence concerning TA's usefulness is mixed.

One of the first empirical studies on charting can be traced back to Levy (1971). He tests all visually subjective patterns, such as head-and-shoulders, triangles, channels, flags, pennants, double-bottoms, and so on, to devise a five-point approach to identify various price patterns, and categorizes all patterns into 32 patterns. According to the findings, none of the 32 patterns showed any forecasting power.

Chang and Osler (1999) utilize the head-and-shoulders pattern as a filter on exchange rates from March 1973 to June 1994. They contend that the head-and-shoulders pattern has forecasting power for the German mark and yen but not for the Canadian dollar, Swiss franc, or French franc. The head-and-shoulders pattern produces statistically significant returns of about $13 \%$ and $19 \%$ per year for the mark and yen, respectively, which are substantially higher than the annual average return (6.8\%) on the S\&P 500 index.

Additionally, Lo, Mamaysky, and Wang (2000) formulate an algorithm for 10 chart patterns, including head-and-shoulders, inverse head-and-shoulders, broadening tops, broadening bottoms, triangle tops, triangle bottoms, rectangle tops, rectangle bottoms, double tops, and double bottoms. They claim that all patterns are profitable for Nasdaq stocks but not for NYSE and AMEX stocks. Dawson and Steeley (2003) extend the work of Lo, Mamaysky, and Wang (2000) by applying the ten patterns to the UK stock market and find that the frequency in both the US and the UK stock markets is similar, with that of the US market being slightly higher. They indicate that profits are unlikely to materialize by using technical analysis strategies.

The research by Brock, Lakonishok, and LeBaron (1992) (BLL, hereafter) treats moving averages and support and resistance as trading rules on the Dow Jones Index from 1897 to 1986 . They find that returns yielded by buying signals are larger than returns yielded by selling signals. Moreover, the return volatilities of buying signals are less than selling signals. Their results provide support for technical analysis strategies.

Bessembinder and Chan $(1995,1998)$ together authored two papers on BLL's trading rules. In the first paper, they apply BLL's trading rules to six Asian stock market indexes, including Japan, Hong Kong, South Korea, Malaysia, Thailand, and Taiwan. They declare that technical trading rules are quite powerful in the emerging markets such as Malaysia, Thailand and Taiwan, yet are poor in the developed markets. In the second paper, they test 26 of BLL's trading rules on the DJIA index from 1926 to 1991. The findings confirm BLL's results, and 
provide evidence that TA can forecast price changes. Ito (1999) tests BLL's trading rules on the Japanese, U.S., Canadian, Indonesian, Mexican and Taiwanese equity indices. He finds that the technical rules have predictive power for all countries, except for the U.S.

Sullivan, Timmermann, and White (1999) further evaluate BLL's trading rules. They set nearly 8,000 parameterizations of trading rules and apply these to the DJIA from 1897 to 1996 . Dividing sample periods into two parts, the 1897-1986 period for comparing with BLL's investigation and the 1987-1996 period for the out-of-sample test, they show that TA can add value for investors in the 1897-1986 period, but fails in the 1987-1996 period. Furthermore, they simulate the Standard and Poor's 500 index futures over a 13-year period, and obtain negative evidence. Nevertheless, none of the studies mentioned above take trading volume into consideration.

Todea and Zoicas-Ienciu (2008) for the Central and Eastern European stock markets emphasize the existence of different stock price behaviors, namely long random walk sub-periods alternating with short ones, characterized by strong linear and/or nonlinear correlations. Recently, Todea and Zoicas-Ienciu (2011) investigate the profitability of the moving average strategy on Romanian currency market. They find that profitability of moving average strategies is not constant over time. The trading rule profits did not declined over time in the case of the Romanian currency market. Hoffmann and Shefrin (2014) investigate individual investors using technical analysis when they trade, and claim that individual investors are not good at using technical analysis. Ko, Lin, Su, and Chang (2014) show that a moving average timing strategy could generate higher returns than the buy-and-hold strategy in the Taiwan stock market. Wang, Jiang, Li, and Zhou (2015) indicate that technical trading rules can produce significant profitability in the Shanghai Securities Composite Index (SSCI), but not in China Securities Index 300 (CSI 300).

\section{Data and Hypotheses}

For implementing, this paper uses data on daily closing prices and volumes for the 50 individual securities posted in the Taiwan 50 index rather than the index. Using data based on individual stocks in the Taiwan 50 avoids problems occasioned by thin trading, as these stocks are the most actively traded and collectively represent $75 \%$ to $80 \%$ of the total market capitalization of the Taiwan Stock Exchange. As stressed by Marshall, Young, and Rose (2006), it is meaningless to examine the merits of TA with a dataset of illiquid or small stocks. Besides, TA is most reliable for actively traded stocks (Morris, 1995). We confirm that our samples address this concern.

We examine the period from October 29, 2002, the date when the Taiwan 50 launched, to December 31, 2013. Stocks that failed to exist for the entire period are eliminated, and the resulting sample includes 43 stocks. Additionally, this study employs the Taiwan Mid-cap 100 component stocks data for the out-of-sample test, and the Taiwan 50 and Taiwan Mid-Cap 100 Index constituent stocks that are not subject to short-selling restrictions. The four hypotheses are shown as follows.

\subsection{Large Volume Effect}

If the ex-ante demand from buyers exceeds the ex-ante supply from sellers, the stock price will rise, and vice versa. In this condition, the volume depends on the quantity of ex-post stock supplied. Therefore, volume directly affects price. Following Gervais, Kaniel, and Mingelgrin (2001), extremely high volume tends to yield positive excess returns. Thus, we propose the first hypothesis.

Hypothesis 1: As the volume enlarges, the stock price will increase as well.

\subsection{Trend Effect}

TA should always be viewed in the context of what happened before (Nison, 1991). Without documenting the correct trend, patterns constructed by TA are irrelevant indicators (Nison, 1991; Morris, 1995; Caginalp \& Laurent, 1998). Otherwise, we will test the momentum effect of the large volume.

Hypothesis 2: When the volume enlarges after a trend, the stock price will increase as well.

\subsection{Anchoring Effect}

As acknowledged by Tversky and Kahneman (1974), the anchoring effect in one's decision may be biased by the impression on human judgment. In accordance with the anchoring effect, we suggest the third hypothesis.

Hypothesis 3: The large volumes will reverse stock prices at peaks or troughs. 


\section{Research Methodology}

\subsection{Trading Rules}

Trading rules tested in this paper are inspired by Brock, Lakonishok, and LeBaron (1992), although our criteria focus on volume. The local maximum volume is defined by the largest volume in the past 20,40 , and 60 days. A buy signal is generated when trading volume surpasses the local maximum volume. Note that return rates are calculated from a buy-and-hold perspective, and thus the positive return rates are suitable for buying, as do the negative return rates are proper to short-sell. Then, three types of trading rules based on volume are examined, that is a buy signal will be emitted after the daily volume exceeds the largest daily volume in the past 20,40 , and 60 days, respectively.

\subsection{Identifying Trends}

This paper observes the general definition of trends outlined by Caginalp and Laurent (1998) using a three-day moving average of prices.

The three-day moving average at time $t$ is defined by:

$$
M A_{3}(t)=[\mathrm{P}(\mathrm{t}-2)+\mathrm{P}(\mathrm{t}-1)+\mathrm{P}(\mathrm{t})] / 3
$$

where $P(t)$ denotes the closing price on day t.

An uptrend on day $t$ is defined by:

$$
M A_{3}(t-6)<M A_{3}(t-5)<\cdots<M A_{3}(t-1)<M A_{3}(t)
$$

Analogously, a downtrend on day $\mathrm{t}$ is defined by:

$$
M A_{3}(t-6)>M A_{3}(t-5)>\cdots>M A_{3}(t-1)>M A_{3}(t)
$$

\subsection{Calculating Profits}

To measure profits yielded by the trading signals defined above, we simulate a trade at the opening price on the day after a signal appears, and we complete the trade at the closing price on the fifth and tenth days of the holding period. Returns are measured as a natural logarithm; a one-day lag mitigates the problem of a nonsynchronous trading bias (Lai, Chen, \& Huang, 2010). Following Brock, Lakonishok, and LeBaron (1992), we examine the profits by raw returns rather than abnormal returns. This approach is more appropriate for short-term trading strategies (Sweeney, 1986). Note that rates of return are calculated from a buy-and-hold perspective. More specifically, positive rates of return following bull signals indicate that the signals correctly forecast the direction of prices, as do negative rates of return for bear signals.

\subsection{Treatment of Transaction Costs and Risk}

Transaction costs and inability to execute at exact prices will reduce returns that are actually obtainable. Transaction costs in the Taiwan stock market include a $0.3 \%$ trading tax and a $0.285 \%$ round-trip brokerage commission. Commissions have become negligible because electronic trading is widespread in Taiwan. Imprecise execution refers to unforeseeable losses arising from impaired order execution, liquidity, and slippage. As Caginalp and Laurent (1998) note, the bid-ask spread is generally $0.1 \%$ to $0.3 \%$. The Taiwan Stock Exchange has the lowest transaction costs in the Asia-Pacific region. We assume transaction and execution costs of $1 \%$ per round-trip trade.

\section{Empirical Results and Discussion}

We first examine the profitability of three rules for 43 in-sample stocks to test their predictive power. The skewness adjusted $\mathrm{t}$-test is used to test the null hypothesis that average returns for the three strategies do not significantly differ from zero. As shown in Table 1, both entire and sub samples, none of their absolute values exceed $1 \%$ significantly, indicating that no rule tested in this study could generate positive returns for 5-day and 10 -day holding periods after assuming $1 \%$ costs.

Table 1. Numbers and returns for entire samples and subsamples

\begin{tabular}{cccccc}
\hline \multirow{2}{*}{ Rule } & \multirow{2}{*}{ No. } & \multicolumn{2}{c}{ 5-day } & \multicolumn{2}{c}{ 10-day } \\
\cline { 3 - 6 } & & Return (\%) & W (\%) & Return (\%) & W (\%) \\
\hline Panel A. Entire samples & & & & \\
$(1,20)$ & 6666 & $0.13 *(0.04)$ & 49.77 & $0.17(0.05)$ & 49.85 \\
$(1,40)$ & 3646 & $0.08(0.38)$ & 49.37 & $0.15(0.22)$ & 49.59 \\
$(1,60)$ & 2594 & $0.09(0.42)$ & 49.31 & $0.16(0.25)$ & 49.23 \\
\hline
\end{tabular}




\begin{tabular}{|c|c|c|c|c|c|}
\hline \multicolumn{6}{|c|}{ Panel B. Uptrends } \\
\hline$(1,20)$ & 555 & $-0.72 *(<0.01)$ & 42.16 & $-0.38(0.17)$ & 43.78 \\
\hline$(1,40)$ & 361 & $-0.88 *(<0.01)$ & 40.17 & $-0.70(0.05)$ & 41.55 \\
\hline$(1,60)$ & 273 & $-0.92 *(<0.01)$ & 38.46 & $-0.93 *(0.03)$ & 40.66 \\
\hline \multicolumn{6}{|c|}{ Panel C. Downtrends } \\
\hline$(1,20)$ & 482 & $0.69 *(0.02)$ & 55.19 & $0.70(0.06)$ & 52.49 \\
\hline$(1,40)$ & 243 & $0.82(0.07)$ & 55.14 & $0.91(0.11)$ & 52.67 \\
\hline$(1,60)$ & 171 & $1.09(0.07)$ & 57.31 & $1.42(0.05)$ & 54.97 \\
\hline
\end{tabular}

Note. This table shows the average returns and winning rates before transaction costs (1\%) for 5 and 10 days. The numbers provided in parentheses represent the $p$-values of skewness adjusted $t$-test. * indicates statistical significance at the $5 \%$ level. "W (\%)" refers to the proportion of positions with returns.

Advocates of TA believe that many participants are willing to sell out their positions at price peaks (Brock, Lakonishok, \& LeBaron, 1992). This selling pressure limits further price appreciation and establishes resistance near the previous peak; by the similar reason, a support price establishes itself near the previous trough, while the anchoring effect proposed by Tversky and Kahneman (1974) seems to agree with this. Table 2 displays the results of anchoring effect, and none profits except for the $(1,60)$ rule at troughs.

Table 2. Numbers and returns for entire samples and subsamples

\begin{tabular}{cccccc}
\hline \multirow{2}{*}{ Rule } & No. & \multicolumn{2}{c}{5 -day } & \multicolumn{2}{c}{ 10-day } \\
\cline { 3 - 5 } & & Return $(\%)$ & $\mathrm{W}(\%)$ & Return $(\%)$ & $\mathrm{W}(\%)$ \\
\hline Panel A. Peaks & & & & \\
$(1,20)$ & 2341 & $-0.31 *(<0.01)$ & 44.64 & $-0.24(0.08)$ & 45.96 \\
$(1,40)$ & 1528 & $-0.32 *(0.01)$ & 44.63 & $-0.14(0.44)$ & 46.60 \\
$(1,60)$ & 1178 & $-0.35 *(0.02)$ & 43.97 & $-0.25(0.22)$ & 44.91 \\
Panel B. Troughs & & & & \\
$(1,20)$ & 1100 & $0.81 *(<0.01)$ & 59.36 & $0.67 *(<0.01)$ & 55.45 \\
$(1,40)$ & 577 & $0.88^{*}(<0.01)$ & 59.10 & $0.70 *(0.03)$ & 54.94 \\
$(1,60)$ & 388 & $1.05 *(<0.01)$ & 61.60 & $0.94 *(0.03)$ & 56.96 \\
\hline
\end{tabular}

Note. This table shows the average returns and winning rates before transaction costs (1\%) for 5 and 10 days. The numbers provided in parentheses represent the $p$-values of skewness adjusted $t$-test. * indicates statistical significance at the $5 \%$ level. "W (\%)" refers to the proportion of positions with returns.

To investigate whether or not abnormal large volume affects its profitability, three rules after uptrends at peaks and after downtrends at troughs with the spike effect are examined. As shown in Table 3, during downtrends at troughs, three rules all generate promising forecasting power for five-day and 10-day holding periods before assumed costs. To be more specific, the $(1,20)$ rule has average returns of $3.49 \%$ and $3.26 \%$ when holding for five and ten days, respectively. The $(1,40)$ rule has average returns of $2.92 \%$ and $3.80 \%$ when holding for five and ten days, respectively. The $(1,60)$ rule has average returns of $4.20 \%$ and $4.89 \%$ when holding for five and ten days, respectively. These findings are consistent with previous studies, such as Brock, Lakonishok, and LeBaron (1992), revealing that buy signals generally generate higher average returns during downtrends than during uptrends.

Table 3. Results for the spike effect

\begin{tabular}{cccccc}
\hline \multirow{2}{*}{ Rule } & \multirow{2}{*}{ No. } & \multicolumn{2}{c}{ 5-day } & \multicolumn{2}{c}{ 10-day } \\
\cline { 3 - 5 } & & Return $(\%)$ & $\mathrm{W}(\%)$ & Return $(\%)$ & $\mathrm{W}(\%)$ \\
\hline Panel A. Uptrends at Peaks & & & & \\
$(1,20)$ & 141 & $-0.35(0.40)$ & 45.39 & $-0.27(0.61)$ & 41.84 \\
$(1,40)$ & 140 & $-0.94 *(0.03)$ & 42.14 & $-0.81(0.14)$ & 38.57 \\
$(1,60)$ & 119 & $-1.00(0.05)$ & 41.18 & $-0.67(0.29)$ & 39.50 \\
Panel B. Downtrend at Troughs & & & & \\
$(1,20)$ & 46 & $3.49 *(<0.01)$ & 69.57 & $3.26 *(0.04)$ & 56.52 \\
$(1,40)$ & 42 & $2.92 *(0.04)$ & 71.43 & $3.80 *(0.03)$ & 59.52 \\
$(1,60)$ & 36 & $4.20 *(<0.01)$ & 69.44 & $4.89 *(0.02)$ & 63.89 \\
\hline
\end{tabular}

Note. This table shows the average returns and winning rates before transaction costs (1\%) for 5 and 10 days. The numbers provided in parentheses represent the $p$-values of skewness adjusted $t$-test. * indicates statistical significance at the $5 \%$ level. "W (\%)" refers to the proportion of positions with returns. 
We explore the data-snooping problem by proceeding with an out-of-sample test. This procedure validates the best-performing trading model, i.e. the spike type of volume after downtrends at troughs, on a different and comparable dataset. Therefore, we selected 43 stocks which are the largest capitalization among the Taiwan Mid-Cap 100 Index for the out-of-sample test, keeping the number of stocks consistent with the in-sample test of 43 stocks. Table 4 summarizes the analogous results for the out-of-sample test, and they agree with the results of the in-sample test. After $1 \%$ assumed costs, three rules yield substantial returns and over $50 \%$ winning rates. The near numbers between in- and out-of-sample tests reveal the robustness of the results.

Table 4. Out-of-sample test result

\begin{tabular}{cccccc}
\hline \multirow{2}{*}{ Rule } & \multirow{2}{*}{ No. } & \multicolumn{2}{c}{5 -day } & \multicolumn{2}{c}{ 10-day } \\
\cline { 3 - 6 } & & Return $(\%)$ & W $(\%)$ & Return $(\%)$ & W $(\%)$ \\
\hline$(1,20)$ & 52 & $4.30 *(<0.01)$ & 73.08 & $3.43 *(<0.01)$ & 63.46 \\
$(1,40)$ & 39 & $3.78 *(<0.01)$ & 66.67 & $3.67 *(<0.01)$ & 58.97 \\
$(1,60)$ & 30 & $3.50 *(0.03)$ & 63.33 & $4.65 *(<0.01)$ & 63.33 \\
\hline
\end{tabular}

Note. This table shows the out-of-sample results in downtrends at troughs. The numbers provided in parentheses represent the $p$-values of skewness adjusted $t$-test. * indicates statistical significance at the $5 \%$ level. "W (\%)" refers to the proportion of positions with returns.

To check the robustness of the results, we emit a trade at the closing price on the day when a signal has finished rather than at the opening price on the day after a signal appears, and then we end the trade at the closing price on the fifth and tenth days of the holding period as well. As expected, the results of Table 5 are very similar to the ones of Panel B of Table 3. This sensitivity analysis makes the results obtained from this study more convincing.

Table 5. Robustness check results

\begin{tabular}{cccccc}
\hline \multirow{2}{*}{ Rule } & No. & \multicolumn{2}{c}{ 5-day } & \multicolumn{2}{c}{ 10-day } \\
\cline { 3 - 6 } & & Return $(\%)$ & W $(\%)$ & $3.05 *(0.05)$ & 60.87 \\
\hline$(1,20)$ & 46 & $3.27 *(<0.01)$ & 69.57 & $3.58^{*}(0.05)$ & 66.67 \\
$(1,40)$ & 42 & $2.70 *(0.04)$ & 71.43 & $4.57 *(0.02)$ & 69.44 \\
$(1,60)$ & 36 & $3.88^{*}(0.01)$ & 72.22 & \\
\hline
\end{tabular}

Note. This table shows the results from adopting closing prices for entering the market in downtrends at troughs. The numbers provided in parentheses represent the $p$-values of skewness adjusted $t$-test. * indicates statistical significance at the 5\% level. "W (\%)" refers to the proportion of positions with returns.

\section{Conclusion}

Using daily data from the Taiwan 50 Index component stocks from October 29, 2002 through December 31, 2013, our empirical analysis has found that outsized trading volume is a precursor of stock price movements. The results also find that trading rules based on volume-based buy signals consistently obtain higher average returns after downtrends at toughs than after uptrends at peaks, indicating asymmetric market responses to the prior conditions for the Taiwan stock market. This asymmetry may be due to Taiwan's institutional factors, asymmetric stock margin systems between buyers and sellers. Our results provide strong evidence that strategies based on trading volume lead to profits in the Taiwan stock market. Our findings confirm Gervais, Kaniel, \& Mingelgrin's (2001) study on trading volume. Abnormal trading volume provides information and investors can make profits by exploiting this useful information.

Main contribution of this study is transferring the viewpoint of price into volume when the technicians implement the trading strategies. The implication of the findings can help practitioners and researchers build a new framework on technical analysis. As to the practitioners, they can extend the concept of volume to create a new method from traditional technical analysis related to price. For the researchers, the abnormally large volume may hint the specific demand or supply involved in it; thus, behavioral finance theories could be further conducted. The limitations of this study is that the abnormally large volume defined by the past 20,40 , and 60 days is more arbitrary. Further research efforts will include superior econometric approaches can be achieved, and additional research can be focused on other active financial markets. 


\section{References}

Alexander, S.S. (1964). Price movements in speculative markets: Trends or random walks. Industrial Management Review, 2(2), 7-26.

Bessembinder, H., \& Chan, K. (1995). The profitability of technical trading rules in the Asian stock markets. Pacific-Basin Finance Journal, 3(2-3), 257-284. http://dx.doi.org/10.1016/0927-538X(95)00002-3

Bessembinder, H., \& Chan, K. (1998). Market efficiency and the returns to technical analysis. Financial Management, 27(2), 5-17. http://dx.doi.org/10.2307/3666289

Blume, L., Easley, D. \& O'Hara, M. (1994). Market statistics and technical analysis: The role of volume. Journal of Finance, 49(1), 153-181. http://dx.doi.org/10.2307/2329139

Brock, W., Lakonishok, J., \& LeBaron, B. (1992). Simple technical trading rules and stochastic properties of stock returns. Journal of Finance, 47(5), 1731-1764. http://dx.doi.org/10.2307/2328994

Caginalp, G., \& Laurent, H. (1998). The predictive power of price patterns. Applied Mathematical Finance, 5(3-4), 181-205. http://dx.doi.org/10.1080/135048698334637

Chang, P. H. K., \& Osler, C. L. (1999). Methodical madness: Technical analysis and the irrationality of exchange-rate forecasts. Economic Journal, 109, 636-661. http://dx.doi.org/10.1111/1468-0297.00466

Dawson, E. R., \& Steeley, J. (2003). On the existence of visual technical patterns in the UK stock market. Journal of Business Finance and Accounting, 30, 263-293. http://dx.doi.org/10.1111/1468-5957.00492

Day, T. E., \& Wang, P. (2002). Dividends, nonsynchronous prices, and the returns from trading the Dow Jones Industrial Average. Journal of Empirical Finance, 9(4), 431-454. http://dx.doi.org/10.1016/S0927-5398(02)00004-X

Fama, E. F., \& Blume, M. (1966). Filter rules and stock market trading. Journal of Business, 39(1), 226-241. http://dx.doi.org/10.1086/294849

Fock, J. H., Klein, C., \& Zwergel, B. (2005). Performance of candlestick analysis on intraday futures data. Journal of Derivatives, 13(1), 28-40.

Gervais, S., Kaniel, R., \& Mingelgrin, D. H. (2001). The high-volume return premium. Journal of Finance, 56, 877-919.

Henry, O. T., \& McKenzie, M. (2006). The impact of short selling on the price-volume relationship: Evidence from Hong Kong. Journal of Business, 79(2), 671-691. http://dx.doi.org/10.1086/499135

Hoffmann, A., \& Shefrin, H. (2014). Technical analysis and individual investors. Journal of Economic Behavior \& Organization, 107, 487-511. http://dx.doi.org/10.1016/j.jebo.2014.04.002

Huang, Z., Heian, J., \& Zhang, T. (2011). Differences of opinion, overconfidence, and high-volume premium. Journal of Financial Research, 34, 1-25. http://dx.doi.org/10.1111/j.1475-6803.2010.01283.x

Ito, A. (1999). Profits on technical trading rules and time-varying expected returns: Evidence from Pacific-Basin $\begin{array}{lllll}\text { equity markets. Pacific-Basin } & \text { Finance }\end{array}$ http://dx.doi.org/10.1016/S0927-538X(99)00008-6

Ko, K., Lin, S., Su, H., \& Chang, H. (2014). Value investing and technical analysis in Taiwan stock market. Pacific-Basin Finance Journal, 26, 14-36. http://dx.doi.org/10.1016/j.pacfin.2013.10.004

Lai, H. W., Chen, C. W., \& Huang, C. S. (2010). Technical analysis, investment psychology, and liquidity provision: Evidence from the Taiwan stock market. Emerging Markets Finance and Trade, 46(5), 18-38. http://dx.doi.org/10.2753/ree1540-496x460502

Levy, R. (1971). The predictive significance of five-point chart patterns. Journal of Business, 44(3), 316-323. http://dx.doi.org/10.1086/295382

Lo, A. W., Mamaysky, H., \& Wang, J. (2000). Foundations of technical analysis: Computational algorithms, statistical inference, and empirical implementation. Journal of Finance, 55(4), 1705-1765. http://dx.doi.org/10.1111/0022-1082.00265

Marshall, B. R., Young, M. R., \& Rose, L. C. (2006). Candlestick technical trading strategies: Can they create value for investors? Journal of Banking \& Finance, 30, 2303-2323. http://dx.doi.org/10.1016/j.jbankfin.2005.08.001

Morris, G. (1995). Candlestick Charting Explained: Timeless Techniques for Trading Stocks and Futures (2nd 
ed.). McGraw-Hill Trade New York.

Murphy, J. (1986). Technical Analysis of the Futures Markets: A Comprehensive Guide to Trading Methods and Applications. New York Institute of Finance.

Nison, S. (1991). Japanese Candlestick Charting Techniques. New York Institute of Finance.

Nison, S. (1997). Japanese Candlestick Charting Techniques: A Contemporary Guide to the Ancient Investment Techniques of the Far East (2nd ed.). New York Institute of Finance.

Park, C. H., \& Irwin, S. H. (2007). What do we know about the profitability of technical analysis? Journal of Economic Surveys, 21(4), 786-826. http://dx.doi.org/10.1111/j.1467-6419.2007.00519.x

Sullivan, R., Timmermann, A., \& White, H. (1999). Data snooping, technical trading rule performance, and the bootstrap. Journal of Finance, 54(5), 1647-1691. http://dx.doi.org/10.1111/0022-1082.00163

Sweeney, R. J. (1986). Beating the foreign exchange market. Journal of Finance, 41(1), 163-182. http://dx.doi.org/10.2307/2328350

Todea, A., \& Zoicas-Ienciu, A. (2008). Episodic dependencies in central and eastern Europe stock markets. Applied Economics Letters, 15(13), 1123-1126. http://dx.doi.org/10.1080/13504850600993614

Todea, A., \& Zoicas-Ienciu, A. (2011). Technical analysis and stochastic properties of exchange rate movements: Empirical evidence from the romanian currency market. Romanian Journal of Economic Forecasting, 14(1), 175-192.

Tversky, A., \& Kahneman, D. (1974). Judgment under uncertainty: Heuristics and biases. Science, 185(4157), 1124-1130. http://dx.doi.org/10.1126/science.185.4157.1124

Wang, S., Jiang, Z., Li, S., \& Zhou, W. (2015). Testing the performance of technical trading rules in the Chinese markets based on superior predictive test. Physica A: Statistical Mechanics and its Applications, 439, 114-123. http://dx.doi.org/10.1016/j.physa.2015.07.029

\section{Copyrights}

Copyright for this article is retained by the author(s), with first publication rights granted to the journal.

This is an open-access article distributed under the terms and conditions of the Creative Commons Attribution license (http://creativecommons.org/licenses/by/4.0/). 